\title{
Resistência antimicrobiana de Pseudomonas aeruginosa em água mineral
}

\section{Renata Resende Prado ${ }^{1 *}$; Eduardo Almeida Freitas ${ }^{1}$; Edson Campos Valadares Júnior ${ }^{1}$; Priscila Cristina $\operatorname{Costa}^{1}$; Mariana Cristina Siqueira ${ }^{1}$; Daise Aparecida Rossi ${ }^{1,2}$}

\author{
${ }^{1}$ Programa de Pós-Graduação em Ciências Veterinárias; \\ ${ }^{2}$ Laboratório de Biotecnologia Animal Aplicada. \\ *Autor para correspondência, E-mail: renatarprado@yahoo.com.br
}

\begin{abstract}
RESUMO. A água mineral é um produto, que merece atenção pelo reconhecimento de sua qualidade, contudo as águas minerais não são estéreis e apresentam microrganismos que lhe são próprios, os autóctones, existentes antes de qualquer tratamento ou processamento. São consideradas as bactérias dos gêneros Pseudomonas, Acinetobacter, Alcaligenes, Flavobacterium, Micrococus, e Bacillus. Estes microrganismos, em especial as do gênero Pseudomonas, após o processo industrial de engarrafamento se multiplicam rapidamente, causando alterações na qualidade na água mineral e desencadeando distúrbios gastrointestinais. O tratamento contra $P$. aeruginosa requer a associação de antibióticos de várias classes, incluindo agentes beta-lactâmicos de terceira e quarta geração, aminoglicosídeos, carbepenemas e quinolonas, entre outros. Pois são bactérias capazes de desenvolver resistência aos antibióticos por meio de diversos mecanismos, como modificação do sistema de permeabilidade, produção de beta-lactamases, transferências de fatores R por conjugação ou super expressão do sistema de efluxo.
\end{abstract}

Palavraschave: Pseudomonas aeruginosa, resistência antimicrobiana, água mineral

\section{Antimicrobial resistance of mineral water in Pseudomonas aeruginosa}

\begin{abstract}
Mineral water is a product that deserves attention for recognition of their quality, however mineral waters are not sterile and microorganisms present of its own , indigenous , existing prior to any treatment or processing. Bacteria of the genera Pseudomonas, Acinetobacter, Alcaligenes, Flavobacterium, Micrococus, and Bacillus are considered. These microorganisms, particularly the genus Pseudomonas, after industrial bottling process multiply rapidly, causing changes in the quality mineral water and triggering gastrointestinal disorders. The treatment against $P$. aeruginosa requires the combination of several classes of antibiotics, including beta- lactams third and fourth generation agents, aminoglycosides, and quinolones carbepenemas, among others . Because bacteria are able to develop resistance to antibiotics through various mechanisms, such as modification of the permeability system, production of beta lactamases, transfer of $\mathrm{R}$ factors by conjugation or overexpression of efflux.
\end{abstract}

Keywords: Pseudomonasa eruginosa, antimicrobial resistance, mineral water

\section{Introdução}

A água mineral natural deve apresentar qualidade que garanta ausência de perigo à saúde do consumidor, e ser captada, processada e envasada obedecendo às condições higiênicosanitárias e as boas práticas de fabricação. A Resolução RDC $\mathrm{n}^{\circ} 173$ de 13 de setembro de 2006 define os procedimentos de boas práticas para industrialização e comercialização de água mineral natural ou de água natural envasada destinada ao consumo humano a fim de garantir sua condição higiênica sanitária (BRASIL, 2006).

As águas minerais, quando atravessam uma superfície de rocha e terra para alcançar determinado nível, perdem grande parte das bactérias e da matéria orgânica em suspensão. Contudo as águas minerais não são estéreis e apresentam microrganismos que lhe são próprios, conhecidos como autóctones, os quais existem antes de qualquer tratamento ou processamento 
(Sabioni \& Silva, 2006). Pertencem a esse grupo, as bactérias dos gêneros Pseudomonas, Acinetobacter, Alcaligenes, Flavobacterium, Micrococus e Bacillus. (Sant'Ana et al., 2003).

A Resolução RDC no 275 de 22 de setembro de 2005 da Agência Nacional de Vigilância Sanitária, regulamenta os padrões de identidade e qualidade da água mineral natural, tendo como microrganismos indicadores de contaminação em águas minerais os coliformes totais, coliformes fecais e/ ou Escherichia coli, clostrídios sulfito redutores, enterococos e Pseudomonas aeruginosa (BRASIL, 2005).

As Pseudomonas aeruginosa têm sido isoladas também em águas recreacionais e a presença destes microrganismos sugere riscos à saúde por meio do contato corporal, ingestão ou inalação, e têm sido propostos como indicadores de qualidade para as águas complementares aos coliformes (Clesceri; Greenberg \& Eaton, 1998).

A importância da $P$. aeruginosa tornou-se maior quando se comprovou sua resistência e capacidade de inibir as bactérias do grupo coliformes (Guilherme; Silva \& Otto, 2000). P. aeruginosa produz uma substância denominada "Pseudocin" (PLS), que causa um efeito bacteriostático sobre o crescimento de E. coli, Aerobacter aerogenes, Citrobacter freundii $e$ Klebsiella sp., dificultando o isolamento destes e alterando os resultados laboratoriais (Coelho et al., 2010). O pigmento antibiótico denominado piocianina também produzido pela $P$. aeruginosa, inibe o desenvolvimento de bactérias do grupo dos coliformes.

Com isso, a transmissão de doenças pela água ainda é uma grande preocupação, apesar vários esforços e de modernas tecnologias que vêm sendo utilizados para a produção de água potável segura. Este problema não se limita aos países em desenvolvimento onde o tratamento de água poderia não existir ou ser insuficiente (Silva et al., 2008).

Estima-se que $80 \%$ de todas as moléstias e mais de um terço dos óbitos dos países em desenvolvimento sejam causados pelo consumo de água contaminada, e, em média, até um décimo do tempo produtivo de cada pessoa se perde devido a doenças relacionadas à água (Moraes \& Jordão, 2002).

Outra preocupação, além das doenças ocasionadas pela presença de microrganismos na água é a resistência antimicrobiana destes microrganismos. As estações de tratamento de esgotos têm sido demonstradas como importante fonte de bactérias resistentes a antibióticos (Novo \& Mania, 2010). Dessa forma, bactérias resistentes a antibióticos são constantemente lançadas com as águas residuais nos recursos hídricos. Muitos destes organismos conduzem genes de resistência a antibióticos, eventualmente, inserida em plataformas genéticas móveis (plasmídeos, transposons e integrons) que são capazes de se espalhar entre a comunidade bacteriana da água e do solo.

Portanto, a água constitui não só uma forma de disseminação de organismos resistentes aos antibióticos entre populações humanas e animais, mas também o caminho pelo qual genes de resistência são introduzidos em ecossistemas bacterianos naturais. Em tais sistemas, bactérias não patogênicas podem servir como um reservatório de genes de resistência (Baquero et al., 2008).

\section{Epidemiologia}

A presença de microrganismos patogênicos na água geralmente é decorrente da poluição por fezes humanas e de animais, provenientes de águas residuárias urbanas e rurais (Gonzalez et al, 1982). Considerando que a maioria dos agentes patogênicos de veiculação hídrica tem em comum sua origem nas fezes de indivíduos doentes, uma condição para a avaliação da qualidade microbiológica da água é o exame de indicadores de contaminação fecal (Amaral et al., 2003). A P. aeruginosa é capaz de crescer abundantemente até em águas puras e sua ocorrência em água mineral deve ser evitada por duas razoes; de um lado, como indicadora da vulnerabilidade ou controle deficiente do ambiente de envase e, de outro, pelo fato de ser um patógeno oportunista (Leclerc \& Moreau, 2002).

A ocorrência de distúrbios gastrintestinais seguintes ao consumo de águas minerais tem revelado que amostras coletadas diretamente do aquífero apresentam população bacteriana de aproximadamente $10-102 \mathrm{UFC} / \mathrm{mL}$ e que essa população aumenta para aproximadamente 103 a106 UFC/mL após o envase (Jayasekara et al., 1998). A contagem de microrganismos autóctones, que embora se encontrem num nível baixo enquanto a água esta em seu ambiente natural, logo após o engarrafamento começam a 
se multiplicar rapidamente (Leclerc \& Moreau, 2002; Rosenberg, 2003).

$\mathrm{O}$ rápido crescimento bacteriano após o envase pode ser causado pela oxigenação da água, pelo aumento da superfície de contato (frasco), pela elevação da temperatura durante o armazenamento e pelos vestígios de nutrientes liberados pela garrafa (Venieri et al., 2006). Levantamentos realizados em águas minerais envasadas em diferentes países têm demonstrado que $P$. aeruginosa é o microrganismo predominantemente encontrado. Essa espécie, patógeno em potencial, contamina a água tanto por ser autóctone e estar largamente distribuída no ambiente, como por falhas no processo de envase (Jayasekara et al., 1998).

A aderência às superfícies internas das embalagens pode explicar a longa sobrevivência de bactérias autóctones na água mineral e com isso a alteração no sabor, odor e turbidez da água. Esses microrganismos podem sobreviver em águas envasadas por vários anos (Jayassekara et al., 1999). A preocupação com a presença de $P$. aeruginosa nas águas minerais reside no fato de serem patógenos oportunistas, causadores de infecções em indivíduos imuno comprometidos, recém-nascidose idosos. Além disso, muitas linhagens de $P$. aeruginosa recuperadas de água potável são resistentes a antibióticos (Sant'Ana et al., 2003).

\section{Características gerais e patogênicas}

A $P$. aeruginosa pertence à família Pseudomona daceae, apresenta-se como bacilo gram negativo, aeróbio, móvel através de um flagelo polar (Who, 2006a).Produz um pigmento fenazínico azul solúvel em água, não fluorescente chamado piocianina. Algumas cepas produzem ainda um pigmento amarelado, apioverdina, um pigmento vermelho, a piorrubina, ou preto, a piomelanina. A combinação do pigmento piocianina com o pioverdina confere uma coloração esverdeada, associada à maioria das cepas de $P$. aeruginosa. (Romão, 2005; Murray, 2003). Uma característica especial da $P$. aeruginosa é a sua capacidade de se desenvolver na água, fonte de poucos nutrientes. Além de ser a causa primária da doença, $P$. aeruginosa é frequentemente monitorizada como um indicador de outras contaminações bacterianas, como as de origem fecal (Silva et al., 2008). A infecção por este patógeno prevalece particularmente entre pacientes com feridas de queimadura, fibrose cística, leucemia aguda, transplante de órgãos e usuários de drogas intravenosas, costumam ocorrer em qualquer local que existe tendência ao acúmulo de umidade e feridas cutâneas exudativas (Konneman et al., 2007). Produz fatores associados à virulência epatogenicidade, como por exemplo, as fímbrias ou pili, as proteases extracelulares (elastase, protease alcalina, hemolisinas), as toxinas extracelulares (exotoxinas A e S) a endotoxina (lipopolissacarídeo), piocianina e derivados, cápsula polissacarídica (exopolissacarídeomucóide) (Romão, 2005).

Porém, um dos principais fatores de virulência refere-se à formação de biofilme que são complexos ecossistemas microbiológicos embebidos em uma matriz de polímeros orgânicos, aderidos a uma superfície. Os biofilmes estão envolvidos em infecções crônicas, lentas, resistentes aos tratamentos, formam-se em superfícies de tecidos naturais e implantes artificiais, o que é uma das características das infecções de válvulas cardíacas, próteses, cateteres, etc., colonizados por Staphylococcus aureus, S. epidermidis, P. aeruginosa entre outras bactérias oportunistas (Macedo, 2004; Barcat, 2005). A espécie de maior importância do gênero é a Pseudomonas aeruginosa, por ser um patógeno humano em potencial (Guilherme; Silva \& Otto, 2000), e está intimamente relacionada a quadros de infecção hospitalar, por características como resistência natural a diversos antibióticos amplamente usados e pela produção de substâncias tóxicas ao homem (Franco \& Landgraf, 1999).

\section{Resistência antimicrobiana}

$\mathrm{O}$ aumento do uso indiscriminado de antibióticos nas práticas médicas, veterinárias e agrárias, podem ser a causa de ambientes aquáticos contaminados constituindo uma rota de disseminação de resistência bacteriana (Fuentefria et al., 2008).

$\mathrm{O}$ efeito dos antibióticos nas bactérias tem sido intensivamente mais estudado em relação a $P$. aeruginosa. Isto ocorre naturalmente em espécies que resistem inicialmente a antibióticos primários como penicilina, tetraciclina e eritromicina. E as P.aeruginosa são geralmente mais suscetíveis a modificações químicas desses agentes (Edberg \& Allen, 2004).Os mecanismos de resistência bacteriana são complexos e variados, e ainda não são completamente 
conhecidos. Sabe-se que o mecanismo mais comum pelo qual os genes de resistência são transferidos é a conjugação (Koneman et al., 2001). A resistência aos antimicrobianos está normalmente associada a um elemento extracromossômico ou plasmídeo, que pode ser transferido entre bactérias da mesma espécie ou de espécies diferentes (Menezes et al., 2004). Contudo, os antimicrobianos podem atuar de diversas maneiras, interferindo em processos metabólicos ou em estruturas do microrganismo. O mecanismo de ação é exercido essencialmente por interferência na síntese da proteína celular, alterações na permeabilidade da membrana citoplasmática, interferência na replicação do cromossomo e interferência na síntese protéica, na qual pode ser observada no quadro 1 (Tenover, 2006).

Quadro 1. Antibióticos e mecanismos de resistência envolvidos

\begin{tabular}{|l|l|}
\hline Antibióticos & Mecanismo de resistência envolvido \\
\hline Betalactâmicos: penicilinas, cefalosporinas, & Inativação enzimática \\
carbapênicos, Aminoglicosídeos, Cloranfenicol & \\
\hline Betalactâmicos (proteínas ligadoras de penicilinas) & Alteração do sítio de ação \\
Aminoglicosídeos (proteínas ribossômicas) & \\
Quinolonas (DNA girase) & \\
Macrolídeos (RNA ribossômico) & Diminuição da permeabilidade \\
\hline Aminoglicosídeos & \\
Quinolonas & \\
Betalactâmicos & \\
Cloranfenicol & Promoção de efluxo \\
\hline Quinolonas & \\
Tetraciclinas &
\end{tabular}

Fonte: Adaptado de Martins (2001).

A resistência pode ser intrínseca ou adquirida através de mutação ou transferência de DNA. A resistência intrínseca da $P$. aeruginosa aos agentes antimicrobianos é decorrente de uma combinação de mecanismos que envolvem permeabilidade da membrana, sistema ativo de efluxo e a inativação enzimática (Romão, 2005). O que, todavia faz da $P$. aeruginosa uma combinação de fatores que se relacionam como: as espécies intrinsicamente resistentes para muitas classes de drogas; sua habilidade para adquirir resistência via mutações, para todos os tratamentos relevantes; seus altos e crescentes padrões de localizadas resistências; e seu frequente papel em sérias infecções (Livermore, 2002).

O mecanismo que influencia a permeabilidade dos antibióticos do meio externo para o meio intracelular relaciona-se à existência de porinas nas membranas, ao tamanho das moléculas do antibiótico e à sua hidrofilia, de tal maneira que seja possível a passagem do fármaco através dos poros (Nikaido, 1989). A hidrofobia dos antimicrobianos explica a resistência intrínseca observada em muitas bactérias gram-negativas, tais como Stenotrophomonas maltophilia e Pseudomonas aeruginosa (Lim \& Webb, 2005).
As cepas de Escherichia coli e de Pseudomonas aeruginosa resistentes à ampicilina e carbenicilina respectivamente, são exemplos de, cuja resistência resultou de mutações que provocaram alterações nas porinas, impedindo a difusão dos antimicrobianos para o espaço periplasmático (Tavares, 2002). A resistência devida à alteração na permeabilidade promovida por genes plasmidiais é pouco frequente. Sua ocorrência é descrita em Pseudomonas aeruginosa resistente à beta-lactâmicos e ao cloranfenicol e em cepas de Escherichia coli resistente ao cloranfenicol. (Benveniste \& Davies, 1973; Shaw, 1984). Pseudomonas spp são resistentes também à aminoglicosídeos, carbapenêmicos e/ou cefalosporinas (Harbarth et al, 2001).

$\mathrm{O}$ uso excessivo de antimicrobianos favoreceu a seleção de organismos resistentes, que vêm se disseminando rapidamente, em diversos ambientes. Assim sendo, a disseminação e o crescente aumento da resistência bacteriana tornaram-se uma questão emergente de saúde pública, justificando-se a necessidade de conhecer a susceptibilidade dos microrganismos comumente causadores de infecções hospitalares (P. aeruginosa e $S$. aureus) isolados de amostras de água para consumo humano (Machado, 2004). 


\section{Tratamento e medidas de controle}

As infecções clinicamente significativas em decorrência da $P$. aeruginosa não devem ser tratadas com um único fármaco, visto que o índice de sucesso é baixo com esse tipo de tratamento e as bactérias podem desenvolver rapidamente resistência. Recomenda-se uma penicilina ativa contra a $P$. aeruginosa (ticarcilina, mezlocilina ou piperacilina) em combinação com uma minoglicosídeo (gentamicina, tobramicina ou amicacina). Outros fármacos ativos contra $P$. aeruginosa incluem aztreonam, imipeném e as quinolonas mais recentes, incluindo a ciprofloxacina. Dentre as cefalosporinas, a ceftazidima e acefoperazona mostram-se ativas contra $P$. aeruginosa (Jawetz, 2005).

De acordo com Murry et al., (2003), a antibioticoterapia das infecções causadas por Pseudomonas aeruginosa é frustrante, porque as bactérias são tipicamente resistentes a maioria dos antibióticos e o paciente infectado que apresenta as defesas comprometidas é incapaz de potencializar a atividade do antibiótico. Durante o tratamento, até mesmo os microrganismos suscetíveis podem se tornar resistentes pela indução da formação de enzimas que inativa os antibióticos (por exemplo, $\beta$-lactamases) ou pela mutação de genes que codificam as proteínas porinas da membrana externa, ou através da resistência mediada por plasmídeos a partir de um microrganismo resistente para outro sensível. Acredita-se que, como muitas bactérias ambientais, a $P$. aeruginosa é encontra no homem em condições sub ótimas, por essa razão, após a ingestão, a colonização se dá de forma passageira. Além disto, pacientes que recebem altas doses em amplo espectro de antibióticos podem ter sua flora alterada (Edberg \& Allen, 2004). Tendo em vista a importância destas características biológicas no meio aquático, torna-se interessante avaliar a resistência aos antibióticos em bactérias heterotróficas oriundas da água mineral, dado o risco que essa hipotética flora autóctone pode representar para lactentes, idosos ou imuno comprometidos (Messi et al., 2005). Os testes de susceptibilidade a antimicrobianos caracterizam-se como uma das ferramentas iniciais na escolha de tais agentes e são os primeiros a indicar resistência (Dubois et al., 2001; Tavares, 2002).

\section{Referências Bibliográficas}

Amaral, L.A., et al. Água de consumo humano como fator de risco à saúde em propriedades rurais. Revista de Saúde Pública. São Paulo, v.37, n.4, 2003.

Baquero, F.; Martinez, J. L. \& Canton, R., 2008. Antibiotics and antibiotic resistance in waterenvironments. Current Opinion in Biotechnology 19, 260-265.

Barcat, J. A. Biofilms. MEDICINA, v. 65, n. 4, p.369-372.Buenos Aires, 2005.

Benviniste, R \& Davies, J. Mechanisms of antibiotic resistance in bacteria.Annus Review of Biochemmistry, Palo Alto, v. 42, p. 471506, jul. 1973.

BRASIL, 2005. Ministério da Saúde. Agência Nacional de Vigilância sanitária. Resolução $\mathrm{n}^{\circ}$ 275 de setembro de 2005. Regulamento Técnico de característicasmicrobiológicas para água mineral natural e água natural. Diário Oficial [da] República Federativa do Brasil, Brasília, DF, de 23 de setembro de 2005.

BRASIL, 2006. Ministério da Saúde. Agência Nacional de Vigilância sanitária. Resolução ${ }^{\circ}$ 173 de setembro de 2006. Regulamento Técnico de Boas Práticas paraIndustrialização e Comercialização de Água Mineral Natural e de Água Natural e a Listade Verificação das Boas Práticas para Industrialização e Comercialização de ÁguaMineral Natural e de Água Natural. Diário Oficial [da] República Federativa do Brasil,Brasília, DF, de 15 de setembro de 2006.

Clesceri, L. S. E.; Greenberg, A. E. \& Eaton, A. D. Standard Methods for the examination of water and waste water. 20 ed. A.P.H.A.; Washington. 1998.

Coelho et al. Avaliação da qualidade microbiológica de águas minerais consumidas na região metropolitana de Recife, Estado de Pernambuco. Acta Scientiarum. Health Sciences, Maringá, v. 32, n. 1, p. 1-8, 2010.

Dubois, V.; Arpin, C.; Melon M.; Melon, B.; Andre, C.; Frigo, C. \& Quentin C. Nosocomial outbreak due to a multiresistent strain of Pseudomonas aeruginosaP12: efficacy of Cefepime-Amikacin therapy and analysis of $\beta$-lactam resistence. $J$ ClinMicrobiol 39:2072-2078, 2001. 
Edberg, S. C. \& Allen, M. J. Virulence and risk from drinking water of heterotrophic plate count bacteria in human population groups. InternationalJournal of Food Microbiology, v. 92,p.255-263, 2004.

Franco, B. D. G. M. \& Landgraf, M. Microbiologia dos Alimentos. São Paulo: Atheneu, 184p, 1999.

Funentefria, D. B.; Ferreira, A. E. \& Graf, T.; Corção, G. Pseudomonas aeruginosa: disseminação de resistência antimicrobiana em efluente hospitalar eágua superficial. Revista da Sociedade Brasileira de Medicina Tropica, vol. 41, n⿳5 5, set - out, p.470-473, 2008.

Gonzalez, R. G; Taylor. M, L. \& Alfaro, G. Estudo bacteriano del agua de consumo en una comunidad Mexicana. Bol Oficina Sanit Panam v.93, p.127-40, 1982.

Guilherme, E. F. M; Silva, J. A. M. \& Otto, S. S. Pseudomonasaeruginosa, como indicador de contaminação hídrica. HigieneAlimentar, São Paulo, v.14, n.76, p.43-47, set. 2000.

Harbarth, S. et al. Parallel analysis of individual and aggregated data on antibiotic exposure and resistance in Gram-negative bacilli.ClinicalInfectiousDiseases, Bethesda, v. 1, n. 33, p. 1462-1468, nov. 2001.

Jawetz, E. Microbiologia médica. Editora Mc Graw-Hill Interamericana do Brasil;Capítulo 17, p.213-214, Rio de Janeiro, 2005.

Jayasekara, N.Y.; Heard, G.M.; Cox, J.M. \& Fleet, G.H. Populations of pseudomonads and related bacteria associatedwith bottled noncarbonated mineral water. Food Microbiology, v. 15, p. 167-176, 1998.

Jayasekara, N.Y.; Heard, G.M.; Cox, J.M. \& Fleet, G.H. Association of micro-organisms with the inner surfaces ofbottles of noncarbonated mineral waters. Food Microbiology, v. 16, p. 115-128, 1999.

Koneman, E. W. et al. Diagnóstico Microbiológico. Editora Médica e Científica, 5 edição. Rio de Janeiro. 2001.

Leclerc, H. \& Moreau, A. 2002. Microbiological safety of natural mineral water.FEMSMicrobiology Reviews 26, 207222.

Lim, S. M \& Webb, S. A. Nosocomial bacterial infections in intensive Care Units. I:
Organisms and mechanisms of antibiotic resistance. Anaesthesia, Bethesda, v. 60, n. 9, p. 887-902, set. 2005.

Livermore, D, M. Of Pseudomonas, porins, pumps and carbapenems.Journal Antimicrobial Chemotherapy, Ottawa, v. 47, n. 3, p. 247-250, mar. 2001.

Macedo, J. A. B. Biofilmes bacterianos, uma preocupação da indústria farmacêutica. Revista Fármacos \& Medicamentos, v.2, n. 7, p. 19 -24. Nov-Dez 2000.Disponível em: <http://www.aguaseaguas.ufjf.br>. Acesso em: 17 mai 2007.

Machado, C. L. Avaliação da presença de microrganismos indicadores de contaminação e patogênicos em líquidos lixiviados do aterro sanitário de Belo Horizonte. 2004. 140p. Dissertação (Mestrado em Saneamento, Meio Ambiente e Recursos Hídricos) Universidade Federal de Minas Gerais, Belo Horizonte, 2004.

Martins, A. M.; Mansur, K. L.; Erthal, F.; Maurício, R. C.; Pereira Filho, J. C. \& Caetano, L. C. Águas Minerais do Estado do Rio de Janeiro. DRM-RJ.Niterói, 2002. Disponível

em:<http://www.ambientebrasil.com.br/comp oser.php3?base $=$./agua/mineral/index.html\&c onteudo=./agua/mineral/minerais.html $>$.

Acesso em: 05 jan 2009.

Menezes, E. A.; Macedo, F. V. V.; Cunha, F. A.; Andrade, M. S. S. \& Rocha, M. V.A.P. Perfil de infecção e resistência aos antimicrobianos de bacilos Gram Negativos Não Fermentadores isolados no Laboratório de Patologia Clínica Dr.Edílson Gurgel, Santa Casa de Misericórdia de Fortaleza - CE. RBCA, v. 36, n. 4, p.209-212. 2004.

Messi, P.; Guerrieri, E. \& Bondi, M. Antibiotic resistance and antibacterialactivity in heterotrophic bacteria of mineral water origin. Science of the Total Environment, v. 346, p.213-219, 2005.

Moraes, D.S.L. \& Jordão, B.Q. Degradação de recursos hídricos e seus efeitossobre a saúde humana. Rev. Saúde Pública, v.36, n. 3, p. 370-374. Jun 2002.Disponível em: <www.scielo.br>. Acesso em: 15 mai 2007.

Murray, P. R.; Baron, E. J.; Jorgensen J H, et al. Manual of Clinical Microbiology,8th Edition, v. 1 , p. $719-725.2003$. 
Novo, A.; Manaia, C.M.; 2010. Factors influencing antibiotic resistance burden in municipalwastewater treatment plants. AppliedMicrobiologyBiotechnology 87, 1157-1166.

Romão, C.M.C.P.A. Estudo de amostras de Pseudomona saeruginosa isoladas em unidades hospitalares quanto os aspectos moleculares e de resistência aos antibióticos, anti-sépticos e desinfetantes. Rio de Janeiro: INCQS/FIOCRUZ,2005.p.1- 9. il. Dissertação (Mestrado) - Instituto Nacional de Controle de Qualidade/Fundação Oswaldo Cruz, Rio de Janeiro.

Rosenverg, F.A. 2003. The microbiology of bottled water. Clinical Microbiology Newsletter, 25 (6), 41-44.

Sabioni, J.G. \& Silva, I.T. Qualidade Microbiológica de Águas Minerais comercializadas em Ouro Preto, MG. Revista Higiene Alimentar, v. 20, n. 143, p.72-78. Ago 2006.

Sant'Ana, A . S.; Silva, S.C.F.; Farini, I.O.Jr.; Amaral, C.H.R. \& Macedo, V.F. Qualidade Microbiológica de Águas Minerais. Ciênc. Tecnol. Aliment., Campinas, v.23, p.190 194. Dez 2003.

Shaw, W. V. Bacterial resistance to chloramphenicol. British Medical Bulletin, Oxford, v. 40, n. 1, p. 36-41, jan. 1984.

Silva, M. E. Z. et al. Comparison of bacteriological quality of tap water an bottledmineral water. International Journal of
Hygiene and Environmental Health, v. 211, p.504-509, 2008.

Tavares, W. Resistência Bacteriana. In: Tavares, W. (editor). Manual de Antibióticos e Quimioterápicos Antiinfecciosos. 3 ed. São Paulo: Atheneu, 2002, p. 55-144.

Tenover, F. C. Mechanisms of antimicrobial resistance in bacteria. American Journal of Medicine.Bethesda, v. 34, n. 5, p. 3-10, jun. 2006.

VenieriI, D.; Vantarakis, A. \& Komninou, G.; Papapetropoulou, M. Microbiological evaluation of bottled noncarbonated("still") water from domestic brands in Greece. International Journal of Food Microbiology, v. 107,p. 68-72, 2006.

WORLD HEALTH ORGANIZATION. Guidelines for drinking-water quality [electronic resource]: incorporating first addendum. Vol. 1, Recommendations. -3 rd ed.p. 29; 50; 146; 289-290, 2006.

\section{Recebido em Agosto 4, 2014}

Aceito em Setembro 23, 2014

License information: This is an open-access article distributed under the terms of the Creative Commons Attribution License, which permits unrestricted use, distribution, and reproduction in any medium, provided the original work is properly cited. 